\title{
Experiment and prediction of water content of sour natural gas with an modified cubic plus association equation of state
}

\author{
Yang Liu' ${ }^{1 *}$, Yun $\mathrm{Zhu}^{1}$, Jun $\mathrm{Zhu}^{2}$ \\ ${ }^{1}$ North China Electric Power University, School of control and Computer Engineering, Beijing 102206, PR China \\ ${ }^{2} J A R I$ Deepsoft Technology CO., LTD, Lianyungang 222006, PR China \\ "Corresponding author: e-mail: liuyang007@ncepu.edu.cn
}

\begin{abstract}
In this work, new experimental value for water content in sour natural gas were reported. In addition, to predict the water content in sour natural gas, a modified cubic plus association equation of state (CPA-EoS) was also proposed. In this model, a new energy parameter a was proposed to make an accurate description of saturated liquid density. Additionally, a temperature dependent binary interaction parameter kij for six binary systems was also obtained. Lastly, a comparison between the prediction results of the modified CPA-EoS and the experimental data was presented, and the results showed that the modified CPA-EoS could predict the water content in sour natural gas with high accuracy, which has an $\mathrm{AAD}$ of $3.6722 \%$ with experimental data in literatures and an $\mathrm{AAD}$ of $1.946 \%$ for experimental data reported in this work.
\end{abstract}

Keywords: water content, sour natural gas, CPA-EoS, binary interaction parameter, PR.

\section{INTRODUCTION}

Water is normally found in extracted natural gases from gas-condensate or petroleum reservoirs, and always exists in liquid water, gas hydrates and ice. Water with any formations could strongly affect the phase behavior of hydrocarbon fluids under certain operation conditions, such as natural gas production, processing facilities or transportation, due to its unique chemical structure. In addition, the acid gases contained in sour natural gas could generate acid liquor, with integrating free water, resulting in the corrosion issue. Therefore, accurate knowledge of predicting water content in sour natural gas is therefore crucial, by calculating dehydrate agents consumption and predicting the aqueous dew points. Additionally, different from sweet natural gas, the existence of $\mathrm{CO}_{2}$ and $\mathrm{H}_{2} \mathrm{~S}$ would make a remarkable effect on the water content. So it is necessary to consider the effect of $\mathrm{CO}_{2}$ and $\mathrm{H}_{2} \mathrm{~S}$ on the water content of sour natural gas.

In order to estimate water content in sour natural gas, many methods have been therefore presented, such as semiempirical methods ${ }^{1,2}$, charts $^{3}$ and thermodynamic models ${ }^{4,5}$. The semiempirical methods as well as charts are exclusively available at special conditions, since they are developed with limited experimental data. Simultaneously, it is difficult to obtain accurate data with chart and the need for interpolations makes the calculation process more complex. The thermodynamic model would describe the composition of natural gas mixtures free to the effect of man-made factors and limitation of application. However, it still has been challenging to accurately describe the phase behavior of water-hydrocarbon system by the available thermodynamic model due to the existence of water with hydrogen bonding.

To describe the effort coming from the hydrogen bonding of water, Kontogeorgis et al. $^{6}$ had proposed a thermodynamic model using the Cubic-Plus-Association equation of state (CPA-EoS). Austegard et al. ${ }^{7}$ utilized this model to estimate water content in methane and carbon dioxide mixtures in equilibrium liquid water, in line with experimental data. With this model, Oliveira et al. ${ }^{8}$ also predicted the solubility of hydrocarbon in water with high accuracy. However, a few researchers have addressed the problem of the modeling phase equilibrium of sour natural gas with CPA-EoS. Although the effect of hydrocarbon would be ignored, to some extent, the existence of acid gas would make significant increase in the solubility of water and it was un-neglected. The available CPA-EoS ${ }^{9-11}$ for sour natural gas always had constant binary interaction parameter and ignored the association between $\mathrm{CO}_{2}$ and $\mathrm{H}_{2} \mathrm{O}$. Therefore, it is difficulty to perform the phase behavior of sour natural gas with high accuracy and still has necessity to improve the CPA-EoS.

In this article, new experimental data of water content in sour natural gas was reported. The hydrate system is a low-temperature system, and the associate interaction between different molecules cannot be ignored. The CPA-EoS would use the association strength between different molecules and the PR-EoS can describe the phase behavior of fluid phase with high accuracy. So in this work, an improved thermodynamic model, using Cubic-Plus-Association equation of state and Peng-Robison equation, for sour natural gas was implemented and validated against experimental data. In order to improve the accuracy of the thermodynamic model, the association between $\mathrm{CO}_{2}$ and $\mathrm{H}_{2} \mathrm{~S}$ was considered in the modified model. Then the thermodynamic model was deduced. In addition, the main parameters of thermodynamic model such as the more accurate energy parameters and temperature dependent binary interaction parameters were proposed.

\section{EXPERIMENTAL SECTION}

\section{Materials used}

High purity grade $\mathrm{CO}_{2}(99.9 \%), \mathrm{H}_{2} \mathrm{~S}(99.9 \%), \mathrm{CH}_{4}$ $(99.9 \%)$ were supplied by Xinyuan gas company. Additionally, the deionized water was used in all the experiments.

\section{Apparatus}

Figure 1 shows a schematic diagram used in this work. A cylindrical cell is made of hastelloy and immerse air bath which controls the temperature. The cell with a volume about $200 \mathrm{~cm}^{3}$ can be operated below $20 \mathrm{MPa}$, 
273.15 to $673.15 \mathrm{~K}$. To accelerate the mixtures establishing vapor-liquid equilibrium, a stirrer was involved in the cell. The temperature of the air bath would be determined by a circulator (PXR4 Fuji Electric, Japan) with a programmable controller. Then the temperature in the air bath and the cell would be measured with thermocouple probe (Omega) which with an accuracy of $\pm 0.1 \mathrm{~K}$. Additionally, a pressure transducer with a maximum error of $\pm 0.01 \mathrm{MPa}$ was utilized to measure the pressure in the cell. To determine the composition of the gas mixtures, a Varian CX 3400 gas chromatograph (Varian Canada Inc., Mississauga, Ont) was utilized.
To complete the phase equilibrium model, the CPA-EoS, which is combined with the well-known Peng-Robison equation (PR), has been applied to determine component fugacities in fluid phase. In addition, the CPA-EoS in terms of pressure $P$ is expressed by Kontogeorgis et al.

$P=P^{\mathrm{PR}}+P^{\text {assoc }}$

where $P^{\mathrm{PR}}$ stands for the physical part of pressure from the Peng-Robinson equation of state and is calculated by Eq. (3)

$P^{\mathrm{PR}}=\frac{\mathrm{R} T}{V-b}-\frac{a}{V(V+b)+b(V-b)}$

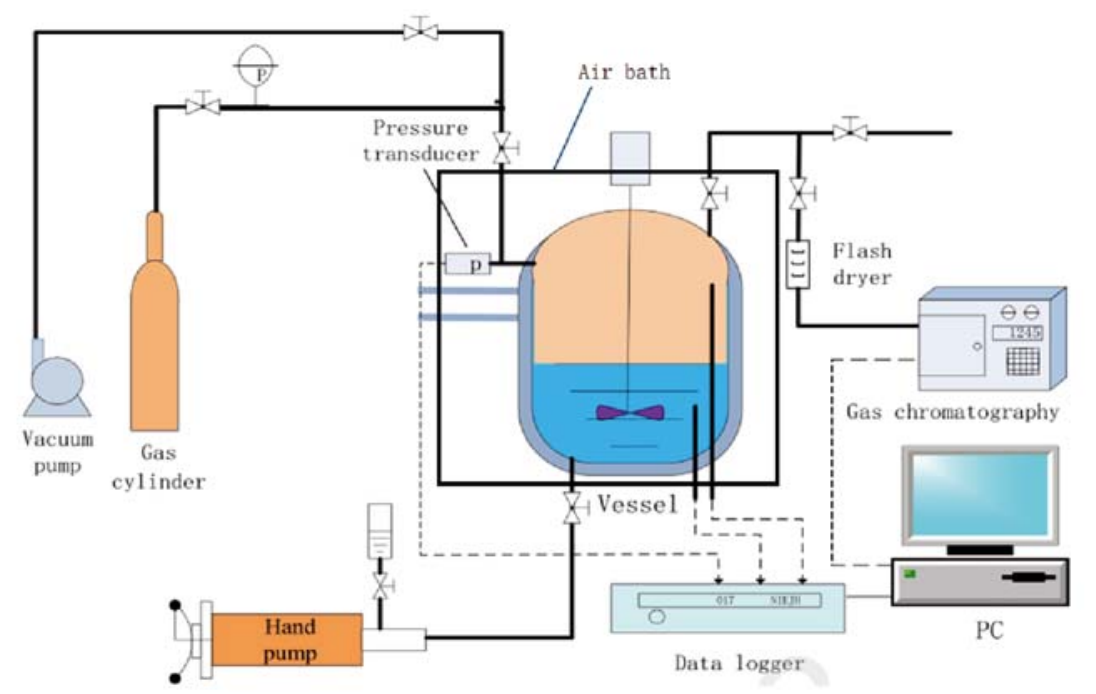

Figure 1. Block Diagram of the apparatus used in this work

\section{Procedure}

The experiments were performed at temperature from $276.5 \mathrm{~K}$ to $305.5 \mathrm{~K}$ and at a pressure with a wide range among $0.32 \mathrm{MPa}$ to $5.78 \mathrm{MPa}$. Before the experiments run, three different compositions of sour natural gas were connected by the pure gas and stored in steel cylinder. Then the average composition of the three mixtures is determined from the same steel cylinder with the gas chromatograph. Prior to experiment, the cell was cleaned by deionized water for three times and then dried three times. With the full preparation, about $100 \mathrm{~cm}^{3}$ of distilled water was injected into the cell firstly. Then the gas was injected into the cell with pump to push the pressure of cell to the desired value. After that, the temperature of air bath was set to the desired value. When there was no systematic variation observed, it is indicated that the sour natural gas was completely saturated. Then the gas composition with gas chromatograph was measured to obtain the water content of sour natural gas at special situation.

\section{Phase Equilibrium Model}

A preliminary study has shown the importance of predicting water content in sour natural gas. In this work, a general phase equilibrium model depending on the equality of fugacity of each component in different phases has been used to model the equilibrium conditions of this quaternary system.

$f_{\mathrm{w}}^{\mathrm{i}}=f_{\mathrm{w}}^{\mathrm{j}}$

where the $f_{\mathrm{w}}^{\mathrm{i}}$ and $f_{\mathrm{w}}^{\mathrm{j}}$ are the fugacity of water in the different phase in equilibrium, such as vapor phase, liquid phase and solid phase, respectively. where $a$ denotes the temperature dependent P-R energy parameter, $b$ refers to the temperature independent $\mathrm{P}-\mathrm{R}$ co-volume parameter and $V_{\mathrm{m}}$ is the molar volume. The association part of pressure, $P^{\text {assoc }}$, is given by Eq. (4)

$P^{\text {assoc }}=\frac{\mathrm{R} T}{2 V}\left[1+\frac{1}{V} \times \frac{\partial \ln g}{\partial(1 / V)}\right] \times \sum_{i} x_{i} \sum_{A_{i}}\left(X_{A_{i}}-1\right)$

$X_{A_{i}}$ is rigorously defined as the mole fraction of molecule $i$ not bonded to the site $\mathrm{A}$ and $x_{i}$ is the mole fraction of the component $i$. where $T$ and $R$ are temperature in Kelvin and the universal gas constant equal to 8.314 $\mathrm{m}^{3} \cdot \mathrm{Pa} \cdot \mathrm{mol}^{-1} \cdot \mathrm{K}^{-1}$.

$X_{A_{i}}=\frac{1}{1+V^{-1} \Delta^{A_{i} B_{j}} \sum_{j} x_{j} \sum_{B_{i}} X_{B_{i}}}$

where the association strength between site $A$ on molecule $i$ and site $B$ on molecule $\mathrm{j}, \Delta^{A_{i} B_{j}}$, is the key quantity of CPA-EoS for the associating components and may be defined as

$\Delta^{A_{i} B_{j}}=g(V) \times\left[\exp \left(\frac{\varepsilon^{A_{i} B_{j}}}{k_{B} T}\right)-1\right] \times \kappa^{A_{i} B_{j}}$

where $\kappa^{A, B_{j}}$ and $\varepsilon^{A_{i} B_{j}}$ are the bonding volume and energy parameters of CPA-EoS, respectively. Additionally, the $k_{\mathrm{B}}$ characterizes the Boltzmann constant. For Pure component, these parameters are listed in Table 1. In this work, the parameters associated with $\mathrm{H}_{2} \mathrm{~S}$ were obtained from the saturation pressure and liquid density value in DIPPR.

In addition, the radial distribution function, $g(V)$, may be expressed as 
Table 1. Pure component for the CPA-EoS

\begin{tabular}{|c|c|c|c|c|}
\hline & $\mathrm{b} \cdot 10^{5}, \mathrm{~m}^{3} \cdot \mathrm{mol}^{-1}$ & $\kappa \cdot 10^{6}$ & $\varepsilon / k_{B}, \mathrm{~K}$ & Reference \\
\hline $\mathrm{H}_{2} \mathrm{O}$ & 1.4584 & 1.8015 & 1738.4 & 12 \\
\hline $\mathrm{H}_{2} \mathrm{~S}$ & 2.8952 & 6.6411 & 453.41 & this work \\
\hline & $T_{\mathrm{c}}, \mathrm{K}$ & $P_{\mathrm{c}}, \mathrm{MPa}$ & $\omega$ & 13 \\
\hline $\mathrm{CO}_{2}$ & 304.19 & 7.382 & 0.2276 & 7 \\
\hline $\mathrm{CH}_{4}$ & 190.56 & 4.599 & 0.0115 & \\
\hline
\end{tabular}

$g(V)=\frac{64 V^{3}-8 V^{2} b}{(4 V-b)^{3}}$

The energy parameter $a$ and co-volume parameter $b$ of non-association components would be predicted by Eq.(8) and Eq.(9)

$a_{i}=a_{0} \times\left[1+c_{1}\left(1-\sqrt{T_{r, i}}\right)+c_{2}\left(1-\sqrt{T_{r, i}}\right)^{2}+c_{3}\left(1-\sqrt{T_{r, i}}\right)^{3}\right]^{2}$

$b_{i}=0.0778 \frac{R T_{c, i}}{P_{c, i}}$

$T_{r, i}=T / T_{c, i}$

The mixing and combining rules for the parameters in the physical part of CPA-EoS, $a$ and $b$, refer to the classical van der Waals equations:

$a=\sum_{i} \sum_{j} x_{i} x_{j} a_{i j}$

$b=\sum_{i} x_{i} b_{i}$

where the classical combination rules are defined by:

$a_{i j}=\sqrt{a_{i} a_{j}} \times\left(1-k_{i j}\right)$ $b_{i j}=\frac{b_{i}+b_{j}}{2}$

where $k_{i j}$ is the binary interaction coefficient between components $i$ and $j$.

For the different associating molecules, the combining rules to calculate the association energy and volume parameters apply CR-1 mixing rules:

$$
\begin{aligned}
& \varepsilon^{A_{i} B_{j}}=\frac{\varepsilon^{A_{i} B_{i}}+\varepsilon^{A_{j} B_{j}}}{2} \\
& \beta^{A_{i} B_{j}}=\sqrt{\beta^{A_{i} B_{i}} \beta^{A_{j} B_{j}}}
\end{aligned}
$$

\section{RESULTS AND DISCUSSION}

\section{The experimental results}

In this work, the water contents of three different sour natural gas compositions in various situation were measured and the results were listed in Table 2.

\begin{tabular}{|c|c|c|c|c|c|c|c|c|}
\hline \multicolumn{3}{|c|}{ Mole fraction $^{a}$} & \multirow{2}{*}{$T, \mathrm{~K}$} & \multirow{2}{*}{$P, \mathrm{MPa}$} & \multirow{2}{*}{ Experimental value, [\%o] } & \multirow{2}{*}{$T, \mathrm{~K}$} & \multirow{2}{*}{$P, \mathrm{MPa}$} & \multirow{2}{*}{ Experimental value, $[\% \circ]$} \\
\hline $\mathrm{CH}_{4}$ & $\mathrm{CO}_{2}$ & $\mathrm{H}_{2} \mathrm{~S}$ & & & & & & \\
\hline \multirow{10}{*}{0.7823} & \multirow{10}{*}{0.0364} & \multirow{10}{*}{0.1813} & 276.5 & 0.32 & 2.401 & 297.5 & 0.32 & 9.235 \\
\hline & & & 276.5 & 0.86 & 0.907 & 297.5 & 0.86 & 3.583 \\
\hline & & & 276.5 & 1.56 & 0.502 & 297.5 & 1.56 & 1.973 \\
\hline & & & 276.5 & 2.72 & 0.28 & 297.5 & 2.72 & 1.08 \\
\hline & & & 276.5 & 5.78 & 0.132 & 297.5 & 5.78 & 0.527 \\
\hline & & & 287.5 & 0.32 & 4.921 & 305.5 & 0.32 & 14.832 \\
\hline & & & 287.5 & 0.86 & 1.843 & 305.5 & 0.86 & 5.589 \\
\hline & & & 287.5 & 1.56 & 1.07 & 305.5 & 1.56 & 2.997 \\
\hline & & & 287.5 & 2.72 & 0.593 & 305.5 & 2.72 & 1.81 \\
\hline & & & 287.5 & 5.78 & 0.286 & 305.5 & 5.78 & 0.846 \\
\hline \multirow{10}{*}{0.8632} & \multirow{10}{*}{0.0402} & \multirow{10}{*}{0.0966} & 276.5 & 0.32 & 2.452 & 297.5 & 0.32 & 9.308 \\
\hline & & & 276.5 & 0.86 & 0.909 & 297.5 & 0.86 & 3.598 \\
\hline & & & 276.5 & 1.56 & 0.504 & 297.5 & 1.56 & 1.998 \\
\hline & & & 276.5 & 2.72 & 0.289 & 297.5 & 2.72 & 1.124 \\
\hline & & & 276.5 & 5.78 & 0.135 & 297.5 & 5.78 & 0.521 \\
\hline & & & 287.5 & 0.32 & 4.994 & 305.5 & 0.32 & 14.997 \\
\hline & & & 287.5 & 0.86 & 1.891 & 305.5 & 0.86 & 5.666 \\
\hline & & & 287.5 & 1.56 & 1.062 & 305.5 & 1.56 & 3.153 \\
\hline & & & 287.5 & 2.72 & 0.61 & 305.5 & 2.72 & 1.826 \\
\hline & & & 287.5 & 5.78 & 0.279 & 305.5 & 5.78 & 1.138 \\
\hline \multirow{10}{*}{0.9327} & \multirow{10}{*}{0.0434} & \multirow{10}{*}{0.0238} & 276.5 & 0.32 & 2.507 & 297.5 & 0.32 & 9.415 \\
\hline & & & 276.5 & 0.86 & 0.951 & 297.5 & 0.86 & 3.688 \\
\hline & & & 276.5 & 1.56 & 0.539 & 297.5 & 1.56 & 2.091 \\
\hline & & & 276.5 & 2.72 & 0.336 & 297.5 & 2.72 & 1.301 \\
\hline & & & 276.5 & 5.78 & 0.19 & 297.5 & 5.78 & 0.711 \\
\hline & & & 287.5 & 0.32 & 4.963 & 305.5 & 0.32 & 15.762 \\
\hline & & & 287.5 & 0.86 & 1.903 & 305.5 & 0.86 & 5.703 \\
\hline & & & 287.5 & 1.56 & 1.132 & 305.5 & 1.56 & 3.273 \\
\hline & & & 287.5 & 2.72 & 0.69 & 305.5 & 2.72 & 2.023 \\
\hline & & & 287.5 & 5.78 & 0.389 & 305.5 & 5.78 & 1.183 \\
\hline
\end{tabular}

Table 2. The experimental results of water content in sour natural gas 


\section{Estimation of Parameters}

Energy Parameter $a$ Since hydrocarbon makes small effect on the water content, this work only considered the existence of $\mathrm{CH}_{4}, \mathrm{CO}_{2}$ and $\mathrm{H}_{2} \mathrm{~S}$. This work firstly refits the parameters of pure component. As Eq.(3) shows, the main parameters for pure component are energy parameter $a$ and volume parameter $b$, which are obtained by the saturated vapor pressure and the saturated liquid density. In order to simplify the calculation process, this work assumed the volume parameter $b$ was consistent, refitting the energy parameter $a$. For non-association component, the $a_{0}$ and $c_{1}$ of Eq.(8) were calculated by the critical temperature, critical pressure and the acentric factor, and $c_{2}, c_{3}$ were equal to zero. However, as $\mathrm{Li}$ et al. $^{\mathbf{1 4}}$ reported, for the components involved in methane-rich natural gas, the equations for parameters $a\left(\mathrm{~J} \cdot \mathrm{m}^{3} / \mathrm{mol}^{2}\right)$ with non-zero $c_{2}$ and $c_{3}$, would obtain more accurate results. This work developed the new parameters $a$ with the saturated liquid density and vapor pressure data of DIPPR database ${ }^{15}$ and the results were listed in Table 3. The objective function used is as below:

$\mathrm{OF}=\sum_{i=1}^{N}\left[\left(\frac{P_{i}^{\mathrm{DIPPR}}-P_{i}^{\text {Calculate }}}{P_{i}^{\mathrm{DIPPR}}}\right)^{2}+\left(\frac{\rho_{i}^{\mathrm{DIPPR}}-\rho_{i}^{\text {Calculate }}}{\rho_{i}^{\mathrm{DIPPR}}}\right)^{2}\right]$
To evaluate the accuracy of the modified CPA-EoS (mCPA-EoS), a comparison between the results of original CPA-EoS and the results of mCPA-EoS was presented and the results were shown in Figure 2.

As shown in Figure 2, a good agreement was obtained in the case of four pure components with the mCPA-EoS. However, the deviations of the original CPA-EoS was un-negligible. In Figure 2(a), there were big deviations between the experimental data and the CPA-EoS results when temperature was lower than $350 \mathrm{~K}$ or between 400-600 K, which agrees with the results from Li et $\mathrm{al}^{\mathbf{1 4}}$. The main reason may be that the effect of the molecular polarity of water is significant in lower temperature and middle temperature range. The similar phenomenon was observed for $\mathrm{H}_{2} \mathrm{~S}$ in lower temperature, showing in Figure 2(b). When temperature was lower than 360 $\mathrm{K}$, the predicted results of the original CPA-EoS were higher than the experimental value. This may be the effect of molecular polarity that decreased the saturated liquid density in lower temperature. When referring to $\mathrm{CH}_{4}$, as showing in Figure 2(c), the deviations of the original CPA-EoS were unacceptable for temperature lower than $170 \mathrm{~K}$. However, the deviations decreased with temperature. It was noted that the original CPA-EoS was unsuitable for the low temperature $\mathrm{CH}_{4}$ system. As shown in Figure 2(d), the original CPA-EoS would

Table 3. Parameters for calculating energy parameter $a$

\begin{tabular}{|c|c|c|c|c|}
\hline & $\mathrm{H}_{2} \mathrm{O}$ & $\mathrm{CO}_{2}$ & $\mathrm{H}_{2} \mathrm{~S}$ & 0.384999 \\
\hline$a_{0}$ & 0.090389 & 0.403124 & 0.254162 & 0.679177 \\
\hline$c_{1}$ & 2.708398 & 0.954412 & -2.551888 & 0.230899 \\
\hline$c_{2}$ & -0.041714 & -7.417771 & -2.834421 & 4.892821 \\
\hline$c_{3}$ & -12.57810 & 23.70622 & 4.006742 & \\
\hline
\end{tabular}

a)

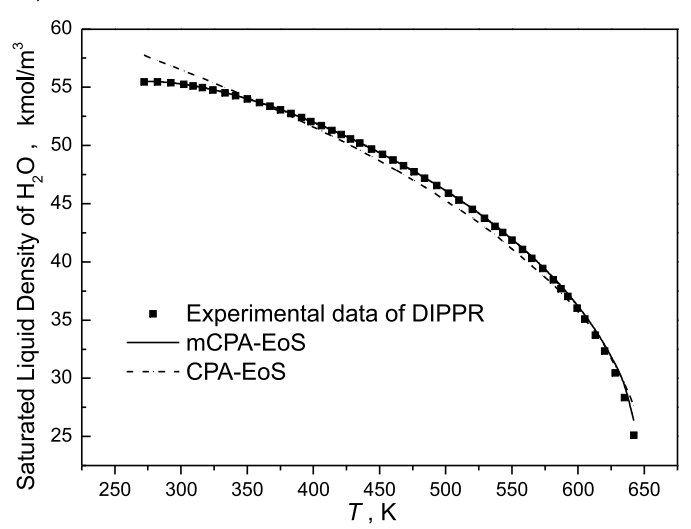

c)

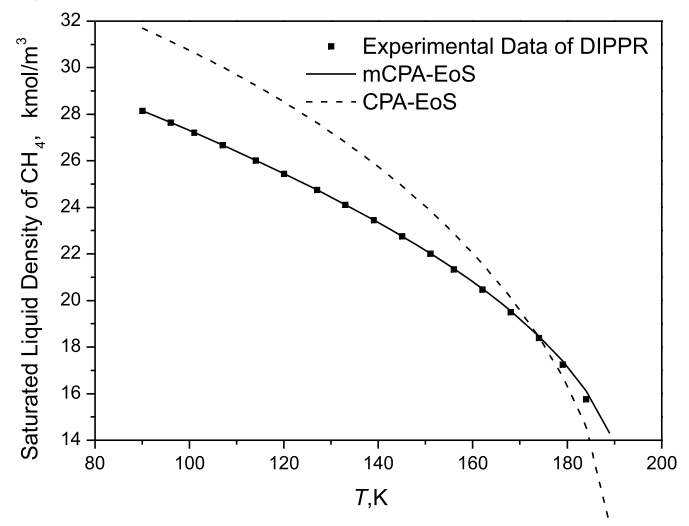

b)

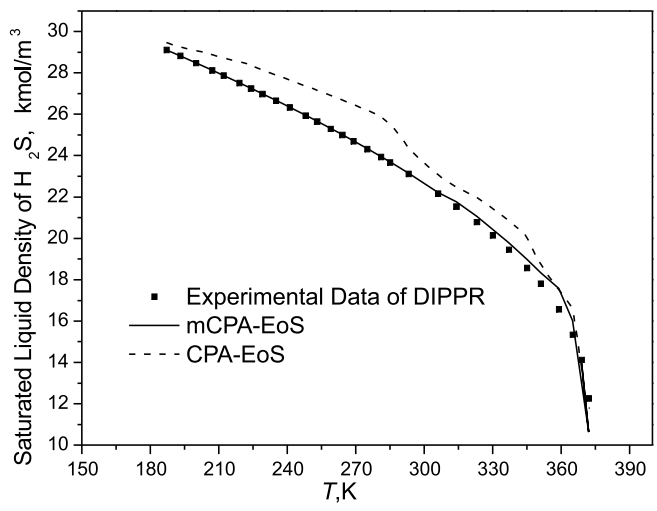

d)

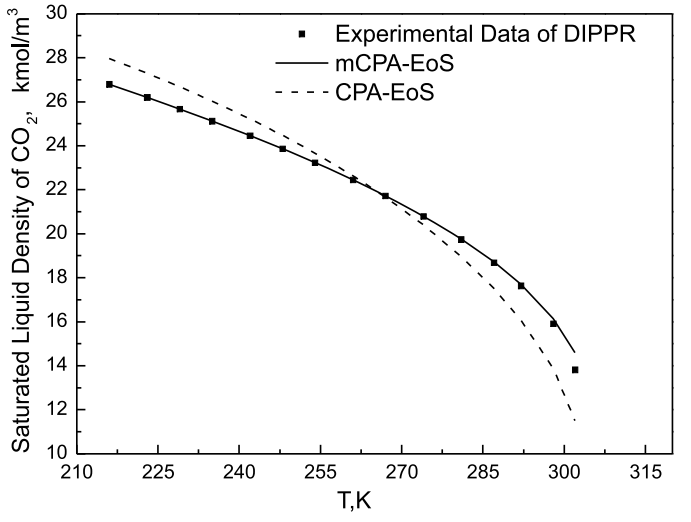

Figure 2. Comparison of the $\mathrm{H}_{2} \mathrm{O}, \mathrm{H}_{2} \mathrm{~S}, \mathrm{CH}_{4}$ and $\mathrm{CO}_{2}$ saturated liquid density between CPA-EoS, mCPA-EoS and the experimental data obtained from DIPPR, respectively 
obtain good agreements for $\mathrm{H}_{2} \mathrm{O}-\mathrm{CO}_{2}$ system around the $273.15 \mathrm{~K}$. While higher results were obtained in lower temperature and lower results were observed reversely. This may be the original CPA-EoS predict the interaction between molecule falsely. For $\mathrm{CH}_{4}$, the association between different molecules makes the saturated liquid density higher in low temperature and lower in high temperature. For $\mathrm{CO}_{2}$ the similar phenomena is observed. But the original model neglects the association between different molecules and thus makes inaccurate results. Above all, with the new developed energy parameter $a$, the modified CPA-EoS would perform the phase behavior of the four binary systems with high accuracy in the studied temperature range.

\section{The Binary Interaction Coefficient $\boldsymbol{k}_{i j}$}

As Ruffine et al. ${ }^{16,17}$ reported, it was a challenge to describe the behavior of binary mixtures by only applying one constant binary interaction coefficient $k_{\mathrm{ij}}$. In addition, the binary interaction coefficient $k_{\mathrm{ij}}$ was sensitive to temperature, while had little influence by pressure. In this work, a temperature dependent $k_{\mathrm{ij}}$ was proposed for the six binary systems, respectively. Water was modeled by the $4 \mathrm{C}$ association scheme. $\mathrm{H}_{2} \mathrm{~S}$ was assumed as $3 \mathrm{~B}$ association scheme. And $\mathrm{CO}_{2}$ was modeled as solvent with one proton acceptor site, which was only associated with water. The related experimental data were listed in Table 4. Meanwhile, the results were shown in Eq.(18) Eq.(23).

$k_{\mathrm{H}_{2} \mathrm{O}-\mathrm{CO}_{2}}=-1.5671 \times 10^{-5} \times T^{2}+0.01008 \times T-1.49552$

$k_{\mathrm{H}_{2} \mathrm{O}-\mathrm{CH}_{4}}=3.17149 \times 10^{-7} \times T^{2}+0.00021 \times T+0.0681$

$k_{\mathrm{H}_{2} \mathrm{O}-\mathrm{H}_{2} \mathrm{~S}}=1.6483 \times 10^{-6} \times T^{2}-0.000534 \times T+0.1354$

$k_{\mathrm{H}_{2} \mathrm{~S}-\mathrm{CO}_{2}}=-6.14 \times 10^{-5} \times T^{2}+0.03524 \times T-5.02174$

$k_{\mathrm{H}_{2} \mathrm{~S}-\mathrm{CH}}=-1.5061 \times 10^{-4} \times T^{2}+0.08101 \times T-10.9912$

$k_{\mathrm{CH}_{4}-\mathrm{CO}_{2}}=7.4562 \times 10^{-8} \times T^{2}+1.5435 \times T+0.0533$

To evaluate the accuracy of the new binary interaction parameters $k_{i j}$, a comparison between the model prediction results and partly experimental value was developed and the results were provided in Figure 3. Additionally, the experimental data used for fitting the $k_{i j}$ were not presented in this part.

As Figure 3 shows, a good agreement had been obtained with the temperature dependent binary interaction parameter. It is demonstrated that the temperature-dependent binary interaction parameters would perform the phase behavior of binary system with high accuracy. Additionally, based on the experimental data utilized to refit the parameters of the thermodynamic model, the adapting temperature range of this model was 274 $\sim 310 \mathrm{~K}$, and the pressure range is $0.1 \sim 15 \mathrm{MPa}$.

\section{Model prediction}

To predict the water content of methane-rich natural gas, a two phase isothermal flash calculation with the modified CPA-EoS was solved with a code embedded in Matlab. Firstly, the dry-based gas composition, temperature and pressure were inputted. The initial phase equilibrium constant $K_{\mathrm{i}}^{0}$ was proposed. Second, a two phase flash was performed. Then a new phase equilibrium constant $K_{\mathrm{i}}$ would be obtained. If the deviation between $K_{\mathrm{i}}^{0}$ and $K_{\mathrm{i}}$ was more than 0.001 , the initial $K_{\mathrm{i}}^{0}$ would be updated and a new iteration would restart. On the contrary, the calculation results were available.

To accelerate convergence, the initial estimated phase equilibrium constant $K_{i}$ was calculated by Eq. $(24)^{\mathbf{3 6}}$.

$K_{i}=\exp \left[\log \left(P_{c, i} / P\right)+5.373\left(1+\omega_{i}\right)\left(1-T_{c, i} / T\right)\right]$

In this work, to evaluate the accuracy of the modified CPA-EoS, a comparison between the predicted water content of methane-rich sour natural gas and the experimental data in literatures ${ }^{\mathbf{3}, 37,38}$ was proposed. Additionally, the absolute deviation and the average absolute deviation was calculated by Eq.(25) and Eq.(26), and the results were listed in Table 5 and Table 6.

$\mathrm{AD}=\frac{\left|x_{w}^{\text {exp. }}-x_{w}^{\text {pre. }}\right|}{x_{w}^{\text {exp. }}} \times 100$

$\mathrm{AAD}=\sum_{\mathrm{i}=1}^{N} \frac{\left|\left(x_{w}^{\text {exp. }}-x_{w}^{\text {pre. }}\right) / x_{w}^{\text {exp }}\right|}{N} \times 100$

Table 4. Source of experimental data of phase equilibria in binary mixtures

\begin{tabular}{|c|c|c|c|c|}
\hline Binary System & Type of equilibrium & $T / \mathrm{K}$ & $\mathrm{P} / \mathrm{MPa}$ & Reference \\
\hline \multirow{4}{*}{$\mathrm{H}_{2} \mathrm{O}-\mathrm{CO}_{2}$} & $V-H / L-H / L-L_{w}$ & $245.15-304.21$ & $0.69-13.79$ & 18 \\
\hline & $L-H / L-L_{w}$ & $274.5-294.5$ & $6.1-10.1$ & 19 \\
\hline & $V-L$ & $274-351$ & $0.2-9.3$ & 20 \\
\hline & $V-L$ & $303-333$ & $10-20$ & 21 \\
\hline \multirow{3}{*}{$\mathrm{H}_{2} \mathrm{O}-\mathrm{H}_{2} \mathrm{~S}$} & $V-L$ & $273.15-363.15$ & 0.101 & 22 \\
\hline & $V-L$ & 278.15-333.15 & $0-0.5$ & 23,24 \\
\hline & $V-L$ & $310.15-543.15$ & $0.6-21$ & 25 \\
\hline \multirow[t]{2}{*}{$\mathrm{CH}_{4}-\mathrm{H}_{2} \mathrm{~S}$} & $V-L$ & $277.6-344.3$ & $1.16-12$ & 26 \\
\hline & $V-L / L-L$ & $186-313$ & $0.043-13.182$ & 27 \\
\hline \multirow{3}{*}{$\mathrm{CH}_{4}-\mathrm{CO}_{2}$} & $V-L$ & $230-270$ & $0.892-3.883$ & 28 \\
\hline & $V-L$ & $230-270$ & $0.894-8.419$ & 29 \\
\hline & $V-L$ & 271.48-199.81 & $1.11-7.9$ & 30 \\
\hline \multirow{3}{*}{$\mathrm{H}_{2} \mathrm{~S}-\mathrm{CO}_{2}$} & $V-L$ & 254.1-350 & $2.03-6.08$ & 31 \\
\hline & $V-L$ & $258.41-313.02$ & $1.00-5.47$ & 32 \\
\hline & $V-L$ & $224.82-363.71$ & $0.69-8.27$ & 33 \\
\hline \multirow[t]{2}{*}{$\mathrm{H}_{2} \mathrm{O}-\mathrm{CH}_{4}$} & $\mathrm{~V}-\mathrm{H}$ & $240-270$ & $3.45-10.34$ & 34 \\
\hline & $V-L$ & $240-313.12$ & $1-25$ & 35 \\
\hline
\end{tabular}



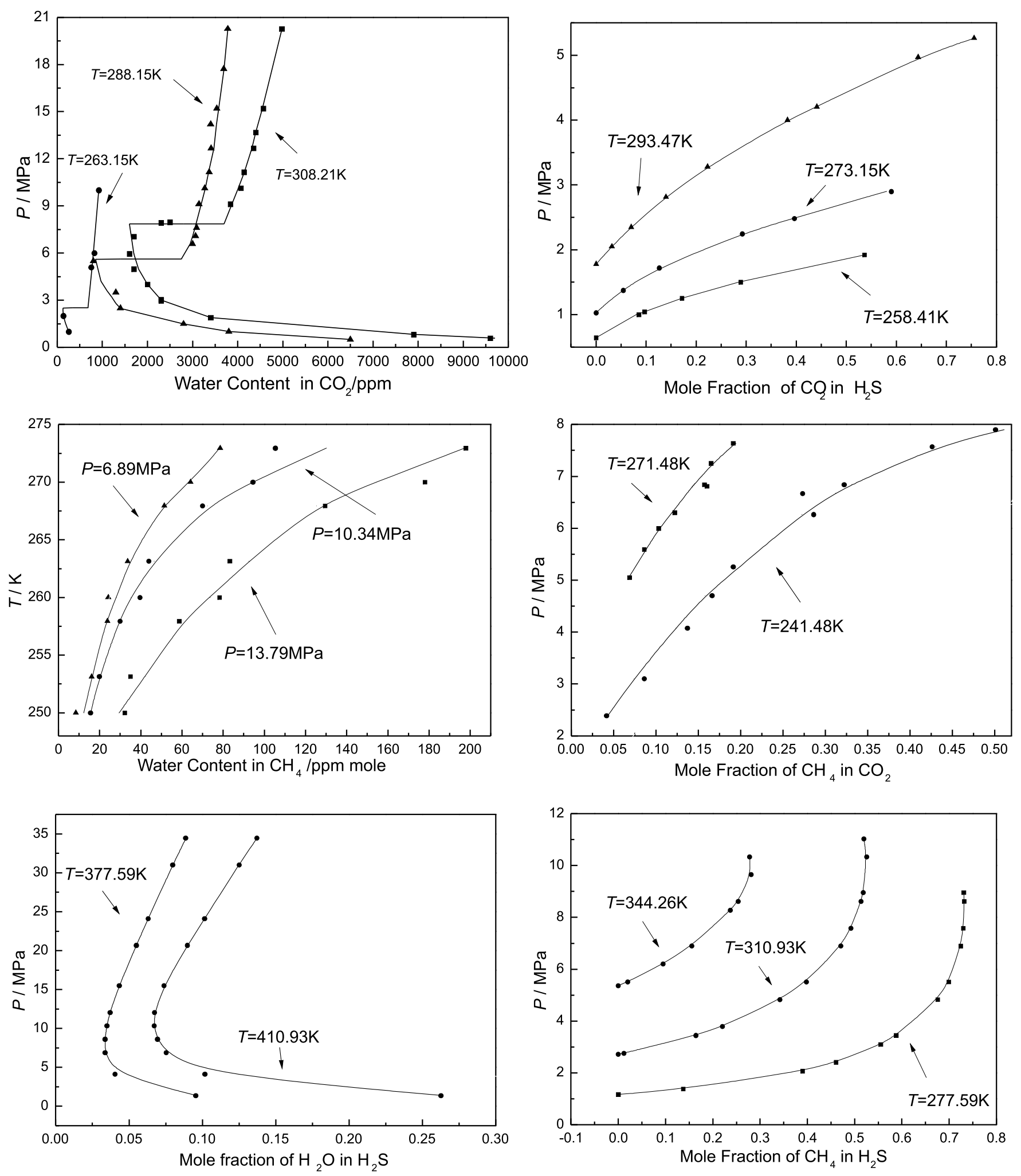

Figure 3. Comparison between the prediction results of mCPA-EoS and experimental data from literatures

where $x_{w}^{\text {exp. }}$ and $x_{w}^{\text {pre. }}$ are the experimental and the predicted water content, respectively, and $N$ is the number of data points.

As Table 5 and Table 6 show, the modified CPA-EoS would describe the phase behavior of methane-rich sour natural gas with high accuracy in all the studied temperature range. In Table 5, the ADs increased slightly with temperature. Especially, the ADs around $273.15 \mathrm{~K}$ were only about $1 \%$, indicating the potential application of predicting water content of sour natural gas might be suitable below $273.15 \mathrm{~K}$. This may be the experimental data used for the parameters fitting were mostly in low temperature range. In Table 6 , the experimental data reported by this work were measured in temperature from $276.5 \mathrm{~K}$ to $305.5 \mathrm{~K}$, consequently, the $\mathrm{ADs}$ were below $3.5 \%$ and the AAD was only $1.946 \%$, which was similar with Table 5. Additionally, the AAD in Table 6 was higher than the ADs around $273.15 \mathrm{~K}$ in Table 5, and the ADs in Table 5 for mixture gas with both $\mathrm{CO}_{2}$ and $\mathrm{H}_{2} \mathrm{~S}$ were higher than sour natural gas with only $\mathrm{CO}_{2}$ or $\mathrm{H}_{2} \mathrm{~S}$. The main reason might be the modified model ignores the association between $\mathrm{CO}_{2}$ and $\mathrm{H}_{2} \mathrm{O}$. In conclusion, the AAD of the modified CPA-EoS was lower than $3.6722 \%$, which disclosed the modified CPA- 
Table 5. The comparison of the estimating value and literatures' experimental data

\begin{tabular}{|c|c|c|c|c|c|c|c|}
\hline \multirow{2}{*}{$T, \mathrm{~K}$} & \multirow{2}{*}{$P, \mathrm{MPa}$} & \multicolumn{3}{|c|}{ Mole fraction } & \multirow{2}{*}{ Experimental value, $[\% 0]$} & \multirow[b]{2}{*}{ mCPA-EoS, [\%o] } & \multirow[b]{2}{*}{$\mathrm{AD},[\%]$} \\
\hline & & $\mathrm{CH}_{4}$ & $\mathrm{CO}_{2}$ & $\mathrm{H}_{2} \mathrm{~S}$ & & & \\
\hline 273.15 & 0.5000 & 0.9983 & 0.0017 & 0.0000 & 1.19 & 1.1804 & 0.8096 \\
\hline 273.15 & 0.5000 & 0.9827 & 0.0173 & 0.0000 & 1.22 & 1.2120 & 0.6548 \\
\hline 273.15 & 0.5000 & 0.7488 & 0.2512 & 0.0000 & 1.76 & 1.7706 & 0.6020 \\
\hline 288.15 & 1.5000 & 0.9983 & 0.0017 & 0.0000 & 1.17 & 1.1895 & 1.6643 \\
\hline 288.15 & 1.5000 & $0.9827^{c}$ & 0.0173 & 0.0000 & 1.16 & 1.1795 & 1.6810 \\
\hline 311.15 & 13.800 & 0.8900 & 0.11 & 0.0000 & 0.81 & 0.8476 & 4.6470 \\
\hline 311.15 & 13.800 & 0.8000 & 0.20 & 0.0000 & 0.81 & 0.8505 & 4.9994 \\
\hline 344.15 & 6.9000 & 0.8900 & 0.11 & 0.0000 & 5.67 & 5.9918 & 5.6749 \\
\hline 344.15 & 6.9000 & 0.8000 & 0.20 & 0.0000 & 5.59 & 5.8514 & 4.6769 \\
\hline 327.15 & 10.300 & 0.9200 & 0.0000 & 0.0800 & 2.21 & 2.1807 & 1.3266 \\
\hline 344.15 & 6.9000 & 0.8300 & 0.0000 & 0.1700 & 5.799 & 5.6018 & 3.4007 \\
\hline 344.15 & 9.4300 & 0.7300 & 0.0000 & 0.2700 & 4.9 & 4.8009 & 2.0221 \\
\hline 344.26 & 2.4680 & 0.7900 & 0.0000 & 0.2100 & 15 & 15.3021 & 2.0139 \\
\hline 344.26 & 4.2120 & 0.8100 & 0.0000 & 0.1900 & 9.3 & 9.5008 & 2.1597 \\
\hline 344.26 & 6.3760 & 0.7100 & 0.0000 & 0.2900 & 6.9 & 7.1331 & 3.3778 \\
\hline 344.26 & 6.9620 & 0.8300 & 0.0000 & 0.1700 & 6.16 & 6.4616 & 4.8956 \\
\hline 344.26 & 9.5950 & 0.7300 & 0.0000 & 0.2700 & 5.2 & 5.5009 & 5.7873 \\
\hline 344.26 & 9.6160 & 0.8400 & 0.0000 & 0.1600 & 4.75 & 5.0517 & 6.3510 \\
\hline 322.04 & 1.3790 & $0.7500^{e}$ & 0.0625 & 0.1875 & 9.37 & 9.0676 & 3.2270 \\
\hline 322.04 & 1.3790 & $0.7500^{e}$ & 0.1875 & 0.0625 & 8.74 & 8.4018 & 3.8693 \\
\hline 322.04 & 10.339 & $0.7500^{e}$ & 0.1875 & 0.0625 & 1.87 & 1.7820 & 4.7043 \\
\hline 322.04 & 10.339 & $0.7500^{e}$ & 0.0625 & 0.1875 & 1.81 & 1.6882 & 6.7284 \\
\hline 366.48 & 1.3790 & $0.7500^{t}$ & 0.1875 & 0.0625 & 59.3 & 57.3057 & 3.3632 \\
\hline 366.48 & 1.3790 & $0.7500^{f}$ & 0.0625 & 0.1875 & 59.67 & 56.7435 & 4.9045 \\
\hline 366.48 & 4.1360 & $0.7500^{e}$ & 0.1875 & 0.0625 & 29.92 & 28.6547 & 4.2291 \\
\hline 366.48 & 10.339 & $0.7500^{f}$ & 0.1875 & 0.0625 & 11.18 & 10.5631 & 5.5175 \\
\hline 366.48 & 10.339 & $0.7500^{f}$ & 0.0625 & 0.1875 & 10.45 & 9.8376 & 5.8607 \\
\hline \multicolumn{7}{|c|}{ AAD, \% } & 3.6722 \\
\hline
\end{tabular}

Table 6. The comparison of the estimating value and experimental data developed in this work

\begin{tabular}{|c|c|c|c|c|c|c|c|c|c|c|}
\hline \multicolumn{3}{|c|}{ Mole fraction $^{a}$} & \multirow{2}{*}{$T, \mathrm{~K}$} & \multirow{2}{*}{$P, \mathrm{MPa}$} & \multirow{2}{*}{$\begin{array}{c}\mathrm{mCPA}- \\
\text { EoS, [\%o] }\end{array}$} & \multirow{2}{*}{$\mathrm{AD},[\%]$} & \multirow{2}{*}{$T, \mathrm{~K}$} & \multirow{2}{*}{$P, \mathrm{MPa}$} & \multirow{2}{*}{$\begin{array}{c}\text { mCPA-Eo, } \\
[\%]]\end{array}$} & \multirow{2}{*}{$A D,[\%]$} \\
\hline $\mathrm{CH}_{4}$ & $\mathrm{CO}_{2}$ & $\mathrm{H}_{2} \mathrm{~S}$ & & & & & & & & \\
\hline \multirow{10}{*}{0.7823} & \multirow{10}{*}{0.0364} & \multirow{10}{*}{0.1813} & 276.5 & 0.32 & 2.421 & 0.826 & 297.5 & 0.32 & 9.515 & 2.943 \\
\hline & & & 276.5 & 0.86 & 0.897 & 1.115 & 297.5 & 0.86 & 3.535 & 1.358 \\
\hline & & & 276.5 & 1.56 & 0.493 & 1.826 & 297.5 & 1.56 & 1.943 & 1.544 \\
\hline & & & 276.5 & 2.72 & 0.276 & 1.449 & 297.5 & 2.72 & 1.11 & 2.703 \\
\hline & & & 276.5 & 5.78 & 0.13 & 1.538 & 297.5 & 5.78 & 0.517 & 1.934 \\
\hline & & & 287.5 & 0.32 & 5.104 & 3.585 & 305.5 & 0.32 & 15.152 & 2.112 \\
\hline & & & 287.5 & 0.86 & 1.895 & 2.744 & 305.5 & 0.86 & 5.625 & 0.640 \\
\hline & & & 287.5 & 1.56 & 1.04 & 2.885 & 305.5 & 1.56 & 3.097 & 3.229 \\
\hline & & & 287.5 & 2.72 & 0.59 & 0.509 & 305.5 & 2.72 & 1.773 & 2.087 \\
\hline & & & 287.5 & 5.78 & 0.277 & 3.249 & 305.5 & 5.78 & 0.823 & 2.795 \\
\hline \multirow{10}{*}{0.8632} & \multirow{10}{*}{0.0402} & \multirow{10}{*}{0.0966} & 276.5 & 0.32 & 2.422 & 1.239 & 297.5 & 0.32 & 9.52 & 2.227 \\
\hline & & & 276.5 & 0.86 & 0.891 & 2.020 & 297.5 & 0.86 & 3.542 & 1.581 \\
\hline & & & 276.5 & 1.56 & 0.494 & 2.024 & 297.5 & 1.56 & 1.948 & 2.567 \\
\hline & & & 276.5 & 2.72 & 0.282 & 2.482 & 297.5 & 2.72 & 1.114 & 0.898 \\
\hline & & & 276.5 & 5.78 & 0.137 & 1.460 & 297.5 & 5.78 & 0.527 & 1.139 \\
\hline & & & 287.5 & 0.32 & 5.106 & 2.193 & 305.5 & 0.32 & 15.197 & 1.316 \\
\hline & & & 287.5 & 0.86 & 1.904 & 0.683 & 305.5 & 0.86 & 5.636 & 0.532 \\
\hline & & & 287.5 & 1.56 & 1.046 & 1.503 & 305.5 & 1.56 & 3.105 & 1.546 \\
\hline & & & 287.5 & 2.72 & 0.597 & 2.178 & 305.5 & 2.72 & 1.776 & 2.815 \\
\hline & & & 287.5 & 5.78 & 0.276 & 1.087 & 305.5 & 5.78 & 1.135 & 0.264 \\
\hline \multirow{10}{*}{0.9327} & \multirow{10}{*}{0.0434} & \multirow{10}{*}{0.0238} & 276.5 & 0.32 & 2.424 & 3.424 & 297.5 & 0.32 & 9.536 & 1.269 \\
\hline & & & 276.5 & 0.86 & 0.923 & 3.034 & 297.5 & 0.86 & 3.628 & 1.654 \\
\hline & & & 276.5 & 1.56 & 0.523 & 3.059 & 297.5 & 1.56 & 2.075 & 0.771 \\
\hline & & & 276.5 & 2.72 & 0.326 & 3.067 & 297.5 & 2.72 & 1.258 & 3.418 \\
\hline & & & 276.5 & 5.78 & 0.185 & 2.703 & 297.5 & 5.78 & 0.691 & 2.894 \\
\hline & & & 287.5 & 0.32 & 5.108 & 2.839 & 305.5 & 0.32 & 15.262 & 3.276 \\
\hline & & & 287.5 & 0.86 & 1.946 & 2.210 & 305.5 & 0.86 & 5.786 & 1.434 \\
\hline & & & 287.5 & 1.56 & 1.112 & 1.799 & 305.5 & 1.56 & 3.293 & 0.607 \\
\hline & & & 287.5 & 2.72 & 0.682 & 1.173 & 305.5 & 2.72 & 1.993 & 1.505 \\
\hline & & & 287.5 & 5.78 & 0.376 & 3.457 & 305.5 & 5.78 & 1.187 & 0.337 \\
\hline \multicolumn{3}{|c|}{ AAD / \% } & \multicolumn{8}{|c|}{1.946} \\
\hline
\end{tabular}

${ }^{a}$ the water-free basis composition

-EoS would predict water content of methane-rich sour gas accurately.

\section{CONCLUSION}

In this paper, new experimental data for water content in sour natural gas were reported, and a modified CPA-Eos to predict water content in methane-rich sour 
natural gas was presented. To improve the accuracy of estimating phase behavior in sour natural gas, the association between $\mathrm{CO}_{2}$ and $\mathrm{H}_{2} \mathrm{O}$ was considered, and accordingly a new energy parameter $a$ as well as a temperature dependent binary interaction parameter $k_{i j}$ were also developed. The results revealed that, with the new energy parameter $a$, the accuracy of predicting saturated liquid density was improved. Comparing the calculated results of mCPA-EoS and the experimental value, the results showed that the ADs of the mCPA-EoS were increasing with temperature. And existence of both $\mathrm{CO}_{2}$ and $\mathrm{H}_{2} \mathrm{~S}$ in sour natural gas would decrease ADs. Above all, the mCPA-EoS would describe the phase behavior of methane-rich sour natural gas with high accuracy, with AADs less than $3.6722 \%$. The results showed that the proposed method to improve the accuracy of thermodynamic model was available. And it might be available for other systems. Additionally, the proposed model has the potential application for predicting the phase behavior, such as dissociation pressure of sour natural gas hydrate.

\section{NOMENCLATURE}

$T=$ absolute temperature in Kelvin

$T_{c}=$ critical temperature

$T_{r}=$ reduced temperature

$P=$ total pressure in $\mathrm{MPa}$

$f=$ fugacity of gas species

$g(1 / V)=$ radial distribution function

$k_{\mathrm{ij}}=$ binary interaction parameter

$V=$ the molar volume

$x=$ the mole fraction in liquid phase

$\mathrm{R}=$ the universal gas constant

$\mathrm{AAD}=$ the average absolute deviation

$\mathrm{AD}=$ the absolute deviation

$a=$ energy parameter

$b=$ co-volume parameter

$c=$ the constant in Eq.(8)

\section{Greek symbols}

$X_{A_{i}}=$ function of free sites of type $A$ belonging to molecule $i$

$\Delta^{A_{i} B_{j}}=$ association strength between two sites $A$ and $B$ belonging to molecules $i$ and $j$, respectively

$\varepsilon^{A_{i} B_{j}}=$ association energy for hydrogen bond between sites $A$ and $B$ belonging to molecules $i$ and $j$, respectively $\kappa^{A_{i} B_{j}}=$ association volume for hydrogen bond between sites $A$ and $B$ belonging to molecules i and j, respectively $k_{B}=$ the Boltzmann constant

$\rho=$ the saturated liquid density

\section{Superscripts}

$0=$ the reference situation

$i=$ the phase

$j=$ the phase

$\mathrm{PR}=$ Peng-Robison equation

assoc $=$ the effect of association part

\section{Subscripts}

$\mathrm{w}=$ water

$\mathrm{H}_{2} \mathrm{~S}=$ hydrogen sulfide

$\mathrm{CO}_{2}=$ carbon dioxide

$\mathrm{CH}_{4}=$ methane $\mathrm{c}=$ the critical situation

$0=$ the reference situation

$\mathrm{i}=$ the component $\mathrm{i}$

$\mathrm{j}=$ the component $\mathrm{j}$

\section{LITERATURE CITED}

1. And, A.H.M. \& Richon, D. (2008). Semiempirical method for determining water content of methane-rich hydrocarbon gas in equilibrium with gas hydrates. Ind. \& Enginee. Chem. Res. 47(2), 451-458. DOI: 10.1021/ie070372h.

2. Lin, Z., Li, L., Zhu, J., Li, Q. \& Fan, J. (2015). Analytical methods to calculate water content in natural gas. Chem.Enginee. Res. \& Design, 93, 148-162. DOI: 10.1016/j.cherd.2014.05.021.

3. GPSA. (1998). Engineering Data Book. eleventh ed. Tulsa: Gas Processors Association.

4. Zirrahi, M., Azin, R., Hassanzadeh, H. \& Moshfeghian, M. (2010). Prediction of water content of sour and acid gases. Fluid Phase Equilibria, 299(2), 171-179. DOI: 10.1016/j. fluid.2010.10.012.

5. Ziabakhsh-Ganji, Z. \& Kooi, H. (2012). An equation of state for thermodynamic equilibrium of gas mixtures and brines to allow simulation of the effects of impurities in subsurface co 2, storage. International J. Greenhouse Gas Control, 11(11), 21-34. DOI: 10.1016/j.ijggc.2012.07.025.

6. Kontogeorgis, G.M., Voutsas, E.C., And, I.V.Y. \& Tassios, D.P. (1996). An equation of state for associating fluids. Ind. \& Enginee. Chem. Res. 35(11), 4310-4318. DOI: 10.1021/ie9600203.

7. Austegard, A., Solbraa, E., Koeijer, G.D. \& Mølnvik, M.J. (2006). Thermodynamic models for calculating mutual solubilities in $\mathrm{h}_{2} \mathrm{O}-\mathrm{CO}_{2}-\mathrm{ch}_{4}$, mixtures. Chem. Enginee. Res. \& Design, 84(9), 781-794. DOI: 10.1205/cherd05023.

8. Oliveira, M.B., Coutinho, J.A.P., \& Queimada, A.J. (2007). Mutual solubilities of hydrocarbons and water with the cpa eos. Fluid Phase Equilibria, 258(1), 58-66. DOI: 10.1016/j. fluid.2007.05.023.

9.Adisasmito, S., Iii, R.J.F. \& Jr, E.D.S. (1991). Hydrates of carbon dioxide and methane mixtures. J. Chem. \& Enginee. Data, 36(1), 68-71. DOI: 10.1021/je00001a020.

10. Dharmawardhana, P.B., Parrish, W.R., \& Sloan, E.D. (1980). Experimental thermodynamic parameters for the prediction of natural gas hydrate dissociation conditions. Le Mans, 19(4), 410-414. DOI: 10.1021/i160076a015.

11. Mekala, P. \& Sangwai, J.S. (2014). Prediction of phase equilibrium of clathrate hydrates of multicomponent natural gases containing co 2, and h 2 s. J. Petrol. Sci. \& Enginee. 116(2), 81-89. DOI: 10.1016/j.petrol.2014.02.018.

12. Li, Z., \& Firoozabadi, A. (2009). Cubic-plus-association equation of state for water-containing mixtures: is "cross association" necessary?. Aiche Journal, 55(7), 1803-1813. DOI: 10.1002/aic.11784.

13. Herslund, P. J., Thomsen, K., Abildskov, J. \& Solms, N.V. (2012). Phase equilibrium modeling of gas hydrate systems for co 2, capture. J. Chem. Thermodyn. 48(5), 13-27. DOI: 10.1016/j.jct.2011.12.039.

14. Li, L., Zhu, L., \& Fan, J. (2016). The application of cpa-vdwp to the phase equilibrium modeling of methane-rich sour natural gas hydrates. Fluid Phase Equilibria, 409, 291-300. DOI: $10.1016 /$ j.fluid.2015.10.017.

15. DIPPR (2011). Design Institute for Physical Properties, Diadem 801.

16. Ruffine, L., P. Mougin, A. \& Barreau, A. (2006). How to represent hydrogen sulfide within the cpa equation of state. Ind. Eng. Chem. Res. 45(22), 7688-7699. DOI: 10.1021/ie0603417.

17. Ruffine, L. \& Trusler, J.P.M. (2010). Phase behaviour of mixed-gas hydrate systems containing carbon dioxide. J. Chem. Thermodyn. 42(5), 605-611. DOI: 10.1016/j.jct.2009.11.019.

18. Song, K.Y., \& Kobayashi, R. (1987). Water content of $\mathrm{CO}_{2}$ in equilibrium with liquid water and/or hydrates. Spe Formation Evaluation, 2(4), 500-508. DOI: 10.2118/15905-PA. 
19. Seo, M.D., Kang, J.W., \& Lee, C.S. (2011). Water solubility measurements of the co2-rich liquid phase in equilibrium with gas hydrates using an indirect method. J. Chem. \& Enginee. Data, 56(5), 2626-2629. DOI: 10.1021/je2001232.

20. Chapoy, A., Mohammadi, A.H., Chareton, A., Tohidi, B. \& Richon, D. (2004). Measurement and modeling of gas solubility and literature review of the properties for the carbon dioxide - water system. Ind. \& Enginee. Chem. Res. 43(7), págs. 1794-1802. DOI: 10.1021/ie034232t.

21. Shigeru Bando, Fumio Takemura, Masahiro Nishio, Eiji Hihara, A. \& Akai, M. (2003). Solubility of co2 in aqueous solutions of nacl at (30 to 60$)^{\circ} \mathrm{C}$ and (10 to 20) mpa. J. Chem. \& Enginee. Data, 48(3). DOI: 10.1021/je0255832.

22.Winkler, L.W..(1906) . Regularity in the absorption of gases by liquids Physical Chemical.

23. Wright, R.H. \& Maass, O. (1932). The electrical conductivity of aqueous solutions of hydrogen sulphide. Canadian J. Res. 6(6), 588-595. DOI: 10.1139/cjr32-047.

24.Wright, R.H. \& Maass, O. (1932). The solubility of hydrogen sulphide in water from the vapor pressures. Canadian J. Res. 6(1), 94-101. DOI: 10.1139/cjr32-006.

25. Selleck, F.T., Carmichael, L.T. \& Sage, B.H. (1952). Phase behavior in the hydrogen sulfide-water system. Industrial \& Engineering Chemistry, 44(9), 2219-2226. DOI: 10.1021/ ie $50513 \mathrm{a} 064$.

26. Reamer, H.H., Sage, B.H., \& Lacey, W.N. (1951). Phase equilibria in hydrocarbon systems - volumetric and phase behavior of the methane-hydrogen sulfide system. Ind. \& Enginee. Chem. 43(4). DOI: 10.1021/ie50496a052.

27. Coquelet, C., Valtz, A., Stringari, P., Popovic, M., Richon, D., Mougin, P. (2014). Phase equilibrium data for the hydrogen sulphide + methane system at temperatures from 186 to $313 \mathrm{~K}$ and pressures up to about $14 \mathrm{MPa}, 383: 94-9$. DOI: $10.1016 / \mathrm{j}$. fluid.2014.09.025.

28. Wei, M.S.W., Brown, T.S., Kidnay, A.J. \& Sloan, E.D. (1995). Vapor + liquid equilibria for the ternary system methane + ethane + carbon dioxide at $230 \mathrm{k}$ and its constituent binaries at temperatures from 207 to 270 k. J. Chem. \& Enginee. Data, 40(4), 726-731. DOI: $10.1021 / \mathrm{je} 00020 \mathrm{a} 002$.

29. Webster, L.A. \& Kidnay, A.J. (2001). Vapor-liquid equilibria for the methane-propane-carbon dioxide systems at $230 \mathrm{k}$ and 270 k. J. Chem. Eng. Data, 46(3), 759-764. DOI: $10.1021 / \mathrm{je} 000307 \mathrm{~d}$.

30. Donnelly, H.G. \& Katz, D.L. (1954). Phase equilibria in the carbon dioxide-methane system. Ind. \& Enginee. Chem. 46(3), 511-517. DOI: 10.1021/ie50531a036.

31. Bierlein, J.A. \& Kay, W.B. (1953). Phase-equilibrium properties of system carbon dioxide-hydrogen sulfide. Ind. \& Enginee. Chem. 45(3), 618-624. DOI: 10.1021/ie50519a043.

32. Chapoy, A., Coquelet, C., Liu, H., Valtz, A. \& Tohidi, B. (2013). Vapour-liquid equilibrium data for the hydrogen sulphide (h $2 \mathrm{~s}$ ) + carbon dioxide (co 2 ) system at temperatures from 258 to $313 \mathrm{k}$. Fluid Phase Equilibria, 356(1-2), 223-228. DOI: 10.1016/j.fluid.2013.07.050.

33. Sobocinski, D.P. \& Kurata, F. (1959). Heterogeneous phase equilibria of the hydrogen sulfide-carbon dioxide system. Aiche J., 5(4), 545-551. DOI: 10.1002/aic.690040217.

34. Aoyagi, K., Song, K.Y., Kobayashi, R., Sloan, E.D., Dharmawardhana, P.B. (1980) (I). The Water Content and Correlation of the Water Content of Methane in Equilibrium with Hydrates, and (II). The Water Content of a High Carbon Dioxide Simulated Prudhoe Bay Gas in Equilibrium with Hydrates. Tulsa: GPA.

35. Antonin Chapoy, A.H.M., Bahman Tohidi, A. \& Richon, D. (2004). A semiempirical approach for estimating the water content of natural gases. Ind. \& Enginee. Chem. Res. 43(22), 7137-7147. DOI: $10.1021 / \mathrm{ie} 049867 \mathrm{~m}$.

36. Michelsen, M.L. JMM (2007). Thermodynamic Models: Fundamentals \& Computational Aspects. second ed. ed. Denmark: Tie-Line Publications.
37. Ng et al., H.J. Ng CJC, H. Schroeder (2001) . Water Content of Natural Gas Systems Containing Acid Gas. Tulsa: GPA Research Report.

38. Lukacs, J. \& Robinson, D.B. (1963). Water content of sour hydrocarbon systems. Society of Petroleum Engineers Journal, 3(4), 293-297. DOI: 10.2118/614-PA. 